\title{
O sistema de busca de filtros de realidade aumentada do aplicativo móvel Instagram: avaliação e recomendações de melhorias baseadas no Design Centrado no Usuário
}

The Instagram mobile app's augmented reality

filter search engine: User Centered Design-based

assessment and improvements recommendations

Dorival Germano Vendrami Junior, Eugenio Andrés Díaz Merino, Giselle Schmidt Alves Dias Merino

interface, design

O aplicativo Instagram possui uma área denominada Stories. Nela, usuários podem

centrado no usuário, gravar vídeos interagindo com filtros que utilizam realidade aumentada. Em 2018, o busca aplicativo passou a permitir que usuários produzissem seus próprios filtros, fazendo a quantidade destes aumentar muito e, assim, o sistema de busca existente em tal área tornou-se ineficiente. O objetivo desta pesquisa foi identificar falhas no sistema de busca de filtros de realidade aumentada da área Stories, do aplicativo Instagram, e sugerir melhorias nesta, baseadas na aplicação de ferramentas de Design Centrado no Usuário. Aplicaram-se as técnicas: Mapeamento de stakeholders, Grupo focal, Mapa da jornada do usuário, Diagrama de fluxo e Diagrama de afinidade, em grupos de usuários representantes da audiência do aplicativo. Como resultado, foi possível compreender como os usuários se relacionam com tal área, as dificuldades impeditivas de ações e os pontos positivos da interação. Dessa forma, foi possível estabelecer recomendações de melhorias, como dividir a área de busca por tags, palavras-chave e usuários, dedicar uma aba para filtros mais utilizados na plataforma e outras, visando facilitar o uso e a recuperação de informações no sistema.

interface, user centred design, search
The Instagram app has an area called Stories. In it, users can record videos interacting with filters that use augmented reality. In 2018, the application started to allow users to produce their own filters, making the number of these increase a lot and, thus, the existing search system in such area became inefficient. The objective of this research was to identify flaws in the search system for augmented reality filters in the Stories area, in the Instagram application, and to suggest improvements in this, based on the application of User-Centered Design tools. The following techniques were applied: Stakeholder Mapping, Focus Group, User Journey Map, Flow Diagram and Affinity Diagram, in groups of users representing the audience of the application. As a result, it was possible to understand how users relate to this area, the difficulties that prevent actions and the positive points of the interaction. In this way, it was possible to 
establish recommendations for improvements, such as dividing the search area by tags, keywords and users, dedicating a tab for filters most used on the platform and others, in order to facilitate the use and retrieval of information in the system.

\section{Introdução}

O avanço do poder de processamento dos aparelhos celulares e das redes de dados permitiu que redes sociais disponibilizassem acesso às suas funcionalidades em tais aparelhos.

A rede social Instagram (Figura 1) permite que seus usuários compartilhem suas experiências com outros utilizadores da plataforma através de fotos e vídeos (FROMMER, 2010). Por se tratar de uma rede social, além desse compartilhamento, os usuários acompanham atualizações de outros utilizadores. Segundo Shane-Simpson (2018), já em 2018, o Instagram era a rede social preferida de universitários americanos e, em novembro de 2019, possuía um bilhão de usuários no mundo (WAKKA, 2018).

Lançada em 2016, Stories é uma área do Instagram que permite publicações curtas, de até 15 segundos e que ficam acessíveis por 24 horas (CARDOSO, 2018). Uma característica importante da área é a possibilidade dos usuários utilizarem filtros (Figura 2) - recursos aplicados sobre as mídias que alteram-nas e criam interações. Uma grande quantidade destes filtros utiliza realidade aumentada para gerar a interação com os vídeos captados, - sendo esta uma tecnologia que conecta informação digital e o mundo real (sCHMALSTIEG; HOLLERER, 2016).
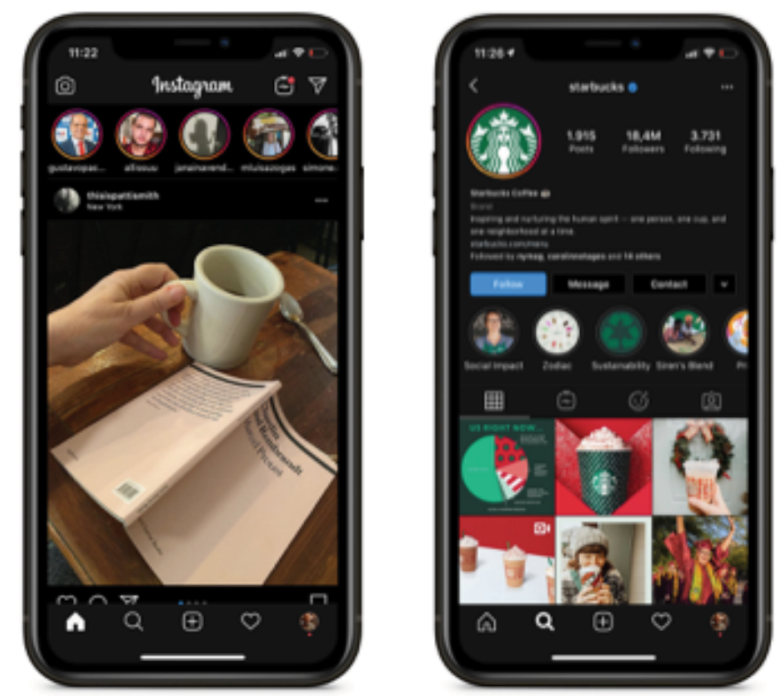

Figura 1 Telas do aplicativo da rede social Instagram. Fonte: www.instagram.com e www.instagram.com/starbucks. 

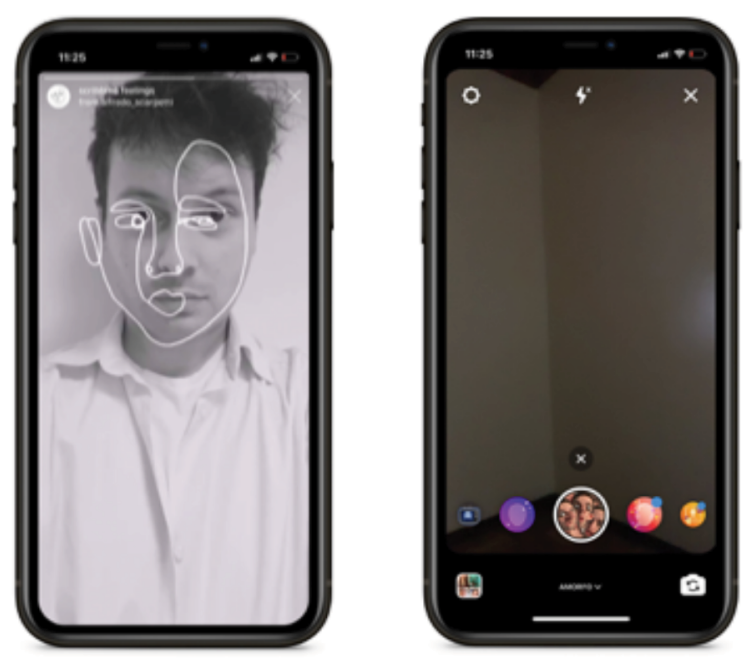

Figura 2 Telas da área Stories do aplicativo Instagram na seção de criação de Stories. Fonte: Instagram.

Na Figura 1, a primeira tela demonstra o feed do aplicativo, onde o usuário acompanha as atualizações de outros perfis. A segunda, um exemplo de página de um usuário. Na Figura 2, a primeira tela demonstra um Story publicado por um usuário. A segunda faz parte do sistema de criação de Stories.

O Stories contava apenas com filtros produzidos pela plataforma ou empresas especializadas e um mecanismo de busca para encontrálos. Porém, em agosto de 2019, a plataforma passou a permitir que usuários criassem filtros e disponibilizam-nos para toda a rede (ALVES, 2019). Dessa forma, a quantidade de filtros disponíveis cresceu significativamente - segundo o Influencer Marketing Hub (GEYSER, 2019), o aplicativo no qual os usuários produzem seus filtros contava, em 2019, com 20 mil usuários.

Mesmo com tal incremento, a plataforma manteve as formas de busca inalteradas (Figura 3). Assim, estas deixaram uma lacuna onde é possível estudar melhorias para o sistema, uma vez que tais recursos se tornaram ineficientes para a nova realidade a qual necessitam atender: organizar e facilitar a recuperação de milhares de filtros à disposição do usuário.

Partindo desta problemática, este artigo analisa a qualidade da interação e de resposta às tarefas nas formas de busca de filtros de realidade aumentada na área Stories do Instagram e indica recomendações para melhoria destas. Este estudo utilizará as ferramentas de DCU Mapeamento de stakeholders, Grupo focal, Mapa da jornada do usuário, Diagrama de fluxo e Diagrama de afinidade.

Este estudo se justifica na medida em que tais enfrentamentos para organização de informações em aplicativos mobile não se limitam ao objeto aqui analisado. Assim, o resultado da análise da interação e suas recomendações dão base para futuros estudos e aplicações em situações de uso análogas. 

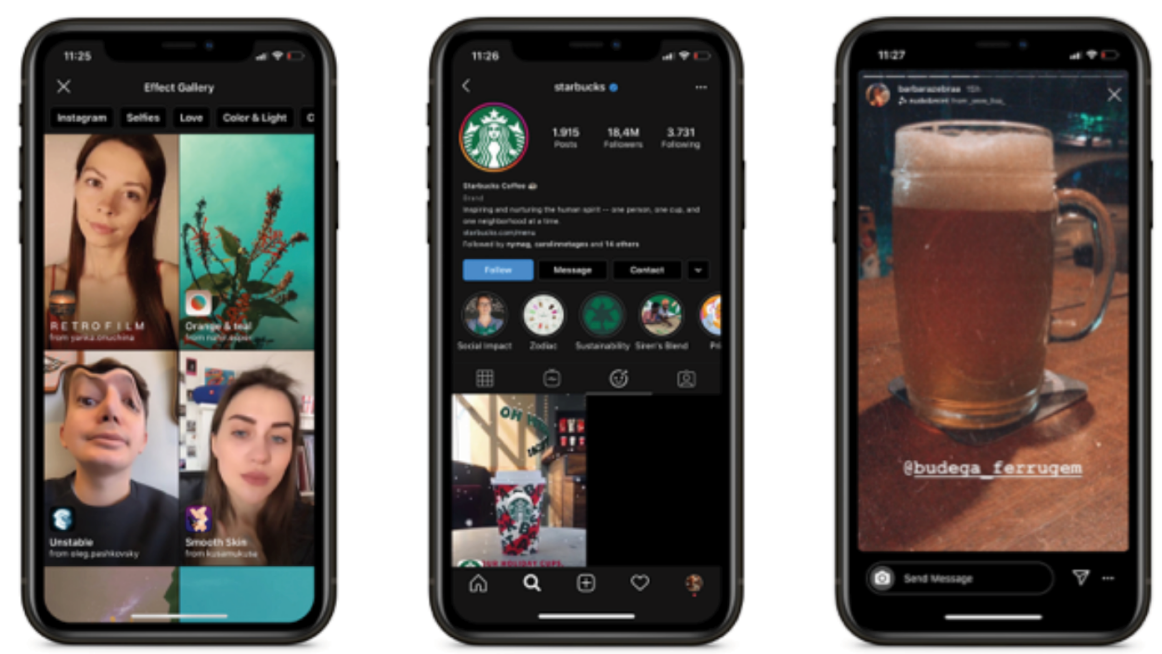

Figura 3 Busca de filtros do Stories: 1. Através da área de busca organizada por tags, onde o usuário seleciona os termos de busca na parte superior; 2. Na página do perfil dos usuários, onde o usuário busca na aba de filtros; 3. No canto superior esquerdo, durante a execução dos Stories: logo abaixo do nome do usuário. Fonte: Instagram e acervo do autor.

\section{Organização da informação em meios digitais}

\subsection{Usabilidade, experiência do usuário e interface}

Segundo Nielsen (2012), a usabilidade é uma questão de sobrevivência na Internet, pois a abundância de sites disponíveis faz com que o usuário não gaste muito tempo no que encontra dificuldade de utilizar. A usabilidade, ainda para Nielsen (2012), é um atributo de qualidade que avalia a facilidade de uso de uma interface, produto ou serviço, em função das variáveis: aprendizagem, eficiência, memorização, erros e satisfação.

A usabilidade é a disciplina associada ao estudo das interfaces e das propriedades desta que possibilitam a utilização do sistema. Cockton (2014), no entanto, traz o conceito de experiência do usuário, sendo que a usabilidade é um dos seus diversos aspectos. Assim, com atuação voltada para o conjunto das interações entre usuários e sistemas e fazendo parte do design de interação, a experiência do usuário não se restringe unicamente a características e atributos do sistema (COCKTON, 2014).

Interfaces são camadas de comunicação entre o usuário que emite comandos e o artefato ou sistema que responde a esses, promovendo assim uma interação em um contexto de uso (JETTER, 2013). E é na interação dos usuários com a interface que ocorre a experiência do usuário, que sintetiza todas as experiências dos usuários com um software, não tratando apenas de funcionalidades, mas de atributos como agradabilidade e percepção de valor (NORMAN; NIELSEN, 2017).

A área Stories utiliza filtros para gerar interações entre seus usuários, sendo que estes podem produzir filtros e compartilhá-los 
com a comunidade. É justamente na interação dos usuários com interfaces como esta da área de busca de filtros que ocorre a experiência do usuário.

O estudo da usabilidade de interfaces de aplicativos móveis de plataformas de streaming já demonstrou as dificuldades enfrentadas por aplicações em tal cenário - como dificuldade de leitura, encontrabilidade e organização da informação (VENDRAMI JUNIOR; GONÇALVES, 2019).

\subsection{Design Centrado no Usuário}

O Design Centrado no Usuário é uma abordagem interativa que posiciona o usuário no centro do processo, considerando suas características, necessidades, desejos, capacidades e limitações. Ela utiliza métodos investigativos auxiliados por ferramentas como mapeamento de stakeholders, grupo focal, mapa da jornada do usuário e diagrama de afinidade (HANINGTON; MARTIN, 2012). Tais ferramentas buscam a participação do usuário ou a colocação do designer na posição deste para que o processo leve em consideração as suas necessidades.

As ferramentas utilizadas nesta pesquisa são:

- Mapeamento de stakeholders: ferramenta para identificação dos usuários de uma aplicação, é ponto de partida para as atividades subsequentes;

- Grupo focal: utilizado para buscar opiniões, sentimentos e atitudes de um grupo de usuários da aplicação;

- Mapa da jornada do usuário: uma visualização das experiências de usuários interagindo com um produto, onde cada momento de interação pode ser analisado individualmente. Durante a jornada, indivíduos selecionados anotam suas interações com o produto, indicando ações, percepções, sentimentos e respostas do produto;

- Diagrama de Fluxo: permite observar como se conectam ideias, objetos e eventos em relação a determinado domínio, quais as sequências de ações possíveis e suas consequências;

- Diagrama de afinidade: externaliza e agrupa observações e insights vindos da pesquisa com usuários. Permite compreender os grupos de qualidades e defeitos de um produto.

\subsection{Arquitetura da Informação}

A arquitetura da informação cria instruções para espaços organizados, lidando com os problemas de reunião, organização e apresentação da informação, tornando simples sua complexidade, planejando estruturas de informações que permitam aos usuários encontrarem seus caminhos para o conhecimento (WURMAN, 1997). 
Assim, em uma época sobrecarregada de informação, causada pelo avanço tecnológico em rede, surge a arquitetura da informação para enfrentar a ansiedade causada por tal situação, buscando organizar os padrões dos dados e facilitar sua apreensão (WURMAN, 1997).

Para Rosenfeld e Morville (2006), a Arquitetura da Informação é a intersecção entre conteúdo, usuários e contexto:

- Conteúdo: documentos, aplicações, serviços e estruturas de conteúdos, como metadados;

- Usuários: o foco é desenhar sistemas que correspondam às suas necessidades;

- Contexto: sistemas de informações fazem parte de contextos organizacionais, dessa forma, também os projetos de Arquitetura da Informação.

\section{Procedimentos Metodológicos}

A pesquisa se caracterizou como aplicada, quanto a sua finalidade, pois indica subsídios para melhoria de um sistema. Quanto a sua abordagem metodológica, é qualitativa na busca de resultados na aplicação das ferramentas de DCU. Por fim, caracterizou-se como exploratória, pois busca subsídios para recomendar melhorias.

A partir da perspectiva do DCU, esta pesquisa avalia a interação dos usuários da rede social Instagram com as formas de busca de filtros da área Stories. Assim, está dividida em duas etapas, sendo que, na primeira, ocorreu a revisão do referencial teórico que embasa a escolha do objeto de estudo, seu entendimento e as ferramentas de avaliação.

A segunda etapa aplicou as ferramentas de DCU apresentadas no capítulo 2, na seguinte ordem:

1. Mapeamento de stakeholders do aplicativo/rede social Instagram;

2. Grupo focal com representantes dos grupos de stakeholders descobertos;

3. Mapa da Jornada do Usuário aplicada com duas voluntárias;

4. Diagrama de Fluxo demonstrando o caminho do usuário na aplicação;

5. Diagrama de Afinidade área de filtros do Instagram;

6. Recomendação de melhorias.

\section{Desenvolvimento}

\subsection{Mapeamento de stakeholders}

Nesta etapa, os pesquisadores identificaram os perfis de público do Instagram a partir da audiência das contas que possuem acesso administrativo. 
A amostra considerou os seguidores de 8 contas, totalizando 520 perfis. Todos perfis brasileiros com, no mínimo, uma postagem em 2019 - para evitar contas abandonadas. Contas privadas, onde a visualização de suas postagens ocorre apenas com permissão e bloqueadas para os pesquisadores foram descartadas.

Foram divididos perfis de acordo com o tipo de interação com a plataforma:

- Pessoal: utiliza sua conta na plataforma exclusivamente para entretenimento. Esta categoria foi dividida por faixa etária e gênero;

- Empresa: conta utilizada para divulgar empresas, produtos ou serviços, não possuindo conteúdo pessoal de usuários. A categoria foi dividida entre empresas com até 30 funcionários e acima disto;

- Influenciador: usuário que possui relevância como celebridades e utilizam suas contas para autopromoção. Esta fatia foi dividida por área de atuação;

- Agência: presta serviços de produção conteúdo para redes sociais de outras empresas;

- Profissional liberal: usuário que utilizam a rede para divulgar seus serviços, mas não vende sua própria imagem. É importante notar que produtores de conteúdo foram alocados em "agência de conteúdo".

Abaixo, resumo dos públicos (Quadro 1):

Quadro 1 Públicos identificados a partir dos seguidores das contas observadas da plataforma.

(Continua)

\begin{tabular}{|c|c|c|}
\hline Público & Divisão & \\
\hline \multirow[t]{3}{*}{ Pessoal } & $20-30$ anos $-60 \%$ & \multirow{3}{*}{$\begin{array}{l}\text { Gênero: } \\
67 \% \text { feminino } \\
33 \% \text { masculino }\end{array}$} \\
\hline & $30-40$ anos $-27 \%$ & \\
\hline & Acima de 40 anos $-13 \%$ & \\
\hline \multirow[t]{2}{*}{ Empresa } & \multicolumn{2}{|c|}{ Empresas com menos de 30 funcionários - 80\% } \\
\hline & \multicolumn{2}{|c|}{ Empresas com mais de 30 funcionários - 20\% } \\
\hline \multirow[t]{4}{*}{ Influenciador } & \multicolumn{2}{|c|}{$\begin{array}{l}\text { Fitness - Professores de educação física, atletas, } \\
\text { nutricionistas, entusiastas e treinadores - } 40 \%\end{array}$} \\
\hline & \multicolumn{2}{|c|}{ Artistas - Músicos, atores, artistas visuais e escritores $-20 \%$} \\
\hline & \multicolumn{2}{|c|}{$\begin{array}{l}\text { Profissionais de comunicação com canais de entretenimento, } \\
\text { críticas e análises - } 32 \%\end{array}$} \\
\hline & \multicolumn{2}{|l|}{ Modelos - $8 \%$} \\
\hline \multirow[t]{2}{*}{ Agência } & \multicolumn{2}{|l|}{ Empresas - 18\% } \\
\hline & \multicolumn{2}{|l|}{ Profissionais liberais - $82 \%$} \\
\hline
\end{tabular}


Quadro 1 Públicos identificados a partir dos seguidores das contas observadas da plataforma.

(Conclusão)

\begin{tabular}{ll}
\hline Público & Divisão \\
\hline Profissional liberal & Coaches $-27 \%$ \\
\cline { 2 - 2 } & Designers $-10 \%$ \\
\cline { 2 - 2 } & Saúde $-20 \%$ \\
\cline { 2 - 2 } & Educação $-23 \%$ \\
\hline & Diversos ou não identificados $-30 \%$ \\
\hline
\end{tabular}

Conforme é possível observar, o público é composto majoritariamente por indivíduos do sexo feminino (67\%) com faixa etária de 20 a 30 anos (60\%), pequenas empresas, influenciadores digitais de área fitness (40\%), profissionais liberais produtores de conteúdo ( $82 \%)$ e coaches $(27 \%)$.

\subsection{Grupo focal}

Replicando os skateholders identificados, o Grupo focal foi composto por: duas usuárias pessoais com idades entre 20 e 30 anos; um usuário pessoal com idade entre 30 e 40 anos; um profissional de empresa de pequeno porte, um influenciador digital, um produtor de conteúdo e dois profissionais liberais, todos com idades entre 20 e 30 anos. Todos os voluntários residem em Jaraguá do Sul, Santa Catarina e possuem ensino superior completo ou em andamento. Além disso, todos são usuários do Instagram há mais de 2 anos e utilizam-no, no mínimo, uma vez por semana.

O Grupo focal foi realizado em novembro de 2019, em uma sala isolada em prédio comercial. Os 8 participantes foram solicitados a executar as seguintes tarefas:

- Acessar o feed do Stories e, ao encontrar um filtro que o agradar, instalar em seu aplicativo;

- Buscar, da forma que achar melhor, um filtro de Stories da marca Starbucks e instalá-lo;

- Pesquisar, na área específica de busca de filtros, um filtro que o agrade e instalá-lo;

- Criar um Story com algum filtro que instalou e publicá-lo;

- Excluir do aplicativo os filtros que foram instalados.

Após executar as tarefas, os usuários discutiram a experiência. O Quadro 2 apresenta os resultados: 
Quadro 2 Descobertas do grupo focal.

\begin{tabular}{l}
\hline Os usuários não possuem dificuldades em instalar e utilizar os filtros; \\
\hline $\begin{array}{l}\text { Todos relataram gastar mais tempo do que gostariam buscando filtros. Seu processo de } \\
\text { busca se resume em encontrar um compartilhamento de Stories de outro usuário utilizando } \\
\text { o filtro. Quatro usuários desconheciam as demais formas de busca; }\end{array}$ \\
\hline Mesmo utilizando um tempo consideravelmente grande na tarefa de buscar filtros, muitas \\
vezes ficaram sem encontrar e desistiram da busca; \\
\hline $\begin{array}{l}\text { Os usuários gostariam de realizar pesquisas de filtros por características destes ou assuntos } \\
\text { relacionados ao conteúdo deles; }\end{array}$ \\
\hline $\begin{array}{l}\text { Na sua maioria, não utilizam a área de busca de filtros, por considerá-la limitada e menos } \\
\text { efetiva que procurar nos Stories de outros usuários; }\end{array}$ \\
\hline Também na sua maioria, desconhecem a aba de filtros criados pelo usuário no perfil deste; \\
\hline $\begin{array}{l}\text { Todos descreveram os métodos de busca e organização como confusos e desorganizados, } \\
\text { fazendo-os gastar muito tempo nas buscas; }\end{array}$ \\
\hline $\begin{array}{l}\text { Sugestão: desenvolver uma forma de seleção por categorias de filtros, como mais baixados, } \\
\text { adicionados recentemente, utilizados por amigos etc. }\end{array}$ \\
\hline
\end{tabular}

\subsection{Mapa da jornada do usuário}

Ficou demostrado no Grupo focal que usuários pessoais são os mais suscetíveis a desistir do uso do recurso estudado. Dessa forma, o Mapa da jornada do usuário mapeou duas usuárias que cobrem tanto essa situação de uso quanto um agrupamento de todas as outras: o uso profissional.

As duas voluntárias possuíam entre 20 e 30 anos e utilizavam a plataforma diariamente há mais de 5 anos. Tais critérios indicam que possíveis problemas registrados não fazem parte de uma curva natural de aprendizado, mas questões que impactam usuários experientes. As voluntárias registraram as suas interações com a aplicação durante um dia inteiro, 3 de novembro de 2019. Os resultados - Tabelas 1 e 2 -, demonstraram um aprofundamento do que já foi descoberto. As voluntárias geraram, respectivamente, 18 e 22 interações, assim as tabelas abaixo apresentam três interações icônicas de cada uma delas.

Nos mapas acima, é possível identificar, além da necessidade de aprimoramento da área de busca, momentos nos quais tal recurso deve ser apresentado ao usuário. No primeiro ponto de contato da Voluntária 01, há a clara indicação da necessidade de formas de organização dos filtros. No segundo ponto de contato da mesma Voluntária, observa-se a necessidade de busca nominal de filtros e por temas.

Quanto à Voluntária 02, percebe-se as mesmas dificuldades e necessidades: no ponto de contato 1 , há a necessidade de organizar os filtros por temas, busca manual ou busca por filtros já vistos; no segundo ponto, busca de filtros por usuário (empresas) e, no terceiro, organização da aba de filtros. 
Tabela 1 Resumo do Mapa da Jornada do Usuário da Voluntária 01 - uso pessoal da plataforma.

\begin{tabular}{llll}
\hline Ponto de contato & $\begin{array}{l}\text { Manhã. Trânsito, no automóvel, } \\
\text { caminho para o trabalho. }\end{array}$ & $\begin{array}{l}\text { Almoço, 13 horas. Cozinha } \\
\text { da empresa, almoçando } \\
\text { com colegas. }\end{array}$ & $\begin{array}{l}\text { Noite, em casa, assistindo } \\
\text { programa na plataforma Netflix } \\
\text { com a mãe. }\end{array}$ \\
\hline Ações da usuária & $\begin{array}{l}\text { Filmar o nascer do } \\
\text { sol diretamente no } \\
\text { Instagram Stories. }\end{array}$ & $\begin{array}{l}\text { Visualizando o feed do Stories, } \\
\text { encontrou um filtro que gostou } \\
\text { em Stories de amigo e repetiu } \\
\text { o efeito com colega. }\end{array}$ & $\begin{array}{l}\text { Tentou encontrar um filtro do } \\
\text { seriado que estava assistindo. } \\
\text { Já havia visto o filtro em um } \\
\text { Stories durante a tarde. }\end{array}$ \\
\hline $\begin{array}{l}\text { Necessidades } \\
\text { da usuária }\end{array}$ & $\begin{array}{l}\text { Buscar o filtro desejado, } \\
\text { filmar e postar. }\end{array}$ & $\begin{array}{l}\text { Instalar o filtro selecionado, } \\
\text { filmar o amigo, aplicar texto } \\
\text { e postar. }\end{array}$ & $\begin{array}{l}\text { Encontrar o filtro que queria } \\
\text { utilizar. Tentou na busca } \\
\text { de filtros, nos usuários que } \\
\text { segue e recorreu ao Google. } \\
\text { Não encontrou. }\end{array}$ \\
\hline $\begin{array}{l}\text { Como se sente } \\
\text { a usuária }\end{array}$ & $\begin{array}{l}\text { Demorou para encontrar o } \\
\text { filtro, mas gostou do resultado. }\end{array}$ & $\begin{array}{l}\text { Teve dificuldade para instalar o } \\
\text { filtro, por isso ficou frustrada. }\end{array}$ & $\begin{array}{l}\text { Ficou incomodada e não } \\
\text { postou nada. Não usou mais } \\
\text { o Stories no dia. }\end{array}$ \\
\hline $\begin{array}{l}\text { Oportunidades } \\
\text { Adicionar forma de catalogar } \\
\text { filtros - como favoritos, } \\
\text { recentemente utilizados, } \\
\text { mais utilizados etc. }\end{array}$ & $\begin{array}{l}\text { Implementar instalações } \\
\text { automáticas ou com instruções } \\
\text { claras para os filtros. }\end{array}$ & $\begin{array}{l}\text { Adicionar ao aplicativo busca } \\
\text { de filtros por palavras-chave } \\
\text { e temas. }\end{array}$ \\
\hline
\end{tabular}

Tabela 2 Resumo do Mapa da Jornada do Usuário da Voluntária 02 - uso profissional da plataforma.

\begin{tabular}{llll}
\hline Ponto de contato & $\begin{array}{l}\text { Trabalho em } \\
\text { estudo fotográfico. }\end{array}$ & $\begin{array}{l}\text { Almoço no restaurante ao } \\
\text { lado do estúdio. }\end{array}$ & $\begin{array}{l}\text { Tarde, intervalo da sessão } \\
\text { de fotos. }\end{array}$ \\
\hline Ações da usuária & $\begin{array}{l}\text { Filmar e postar bastidores } \\
\text { da sessão de fotos, utilizando } \\
\text { filtro já salvo. }\end{array}$ & $\begin{array}{l}\text { Acessar perfil de empresas e } \\
\text { Stories destas. Instala filtros } \\
\text { para utilizar posteriormente. }\end{array}$ & $\begin{array}{l}\text { Postar vídeos feitos durante a } \\
\text { tarde. Enviar vídeos ao Stories, } \\
\text { buscar filtros, aplicar textos } \\
\text { e postar. }\end{array}$ \\
\hline $\begin{array}{l}\text { Necessidades } \\
\text { da usuária }\end{array}$ & $\begin{array}{l}\text { Aplicar filtros, animações e } \\
\text { textos nos vídeos. Postar. }\end{array}$ & $\begin{array}{l}\text { Instalar filtros a partir de Stories } \\
\text { de usuários e buscar filtros. }\end{array}$ & Buscar filtros, aplicar e postar. \\
\hline $\begin{array}{l}\text { Como se sente } \\
\text { a usuária }\end{array}$ & $\begin{array}{l}\text { Um pouco contrariada por não } \\
\text { conseguir encontrar um filtro } \\
\text { que gostou no dia anterior. }\end{array}$ & $\begin{array}{l}\text { Frustrada, pois não consegue } \\
\text { buscar os termos que gostaria } \\
\text { e por não poder organizar } \\
\text { sua área de filtros, que possui } \\
\text { grande quantidade de opções. }\end{array}$ & $\begin{array}{l}\text { Gostaria que a aba de filtros } \\
\text { pudesse ser organizada, pois } \\
\text { está tomando cada vez mais } \\
\text { tempo buscar opções. }\end{array}$ \\
\hline $\begin{array}{lll}\text { Oportunidades } \\
\text { Implementar buscas de filtros }\end{array}$ & $\begin{array}{l}\text { Implementação de busca } \\
\text { textual de filtros e formas } \\
\text { de organização daqueles já } \\
\text { instalados pelo usuário. }\end{array}$ & $\begin{array}{l}\text { Implementar formas de } \\
\text { organização daqueles já } \\
\text { instalados pelo usuário. }\end{array}$ \\
\hline $\begin{array}{l}\text { visualizados, filtros utilizados } \\
\text { por amigos etc. }\end{array}$ & & & \\
\hline
\end{tabular}

\subsection{Diagrama de fluxo}

Como suporte para a técnica seguinte (Diagrama de afinidade), foi montado o Diagrama de fluxo da aplicação, com a finalidade de guiar os pesquisadores com as interações possíveis na ferramenta (Figura 4): 


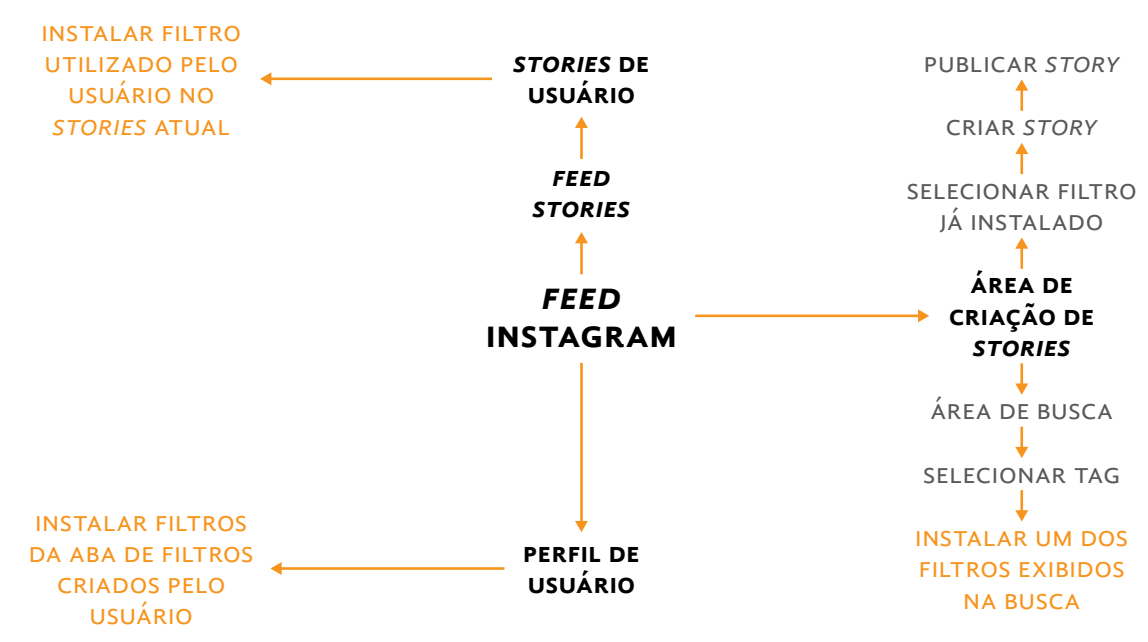

Figura 4 Diagrama de fluxo das formas de busca e utilização de filtros para Stories. Fonte: desenvolvido pelo autor.

\subsection{Diagrama de afinidade}

O Diagrama de afinidade foi aplicado em dezembro de 2019, contando um grupo de oito voluntários, novamente divididos no padrão de usuários identificado no Mapa de stakeholders (Quadro 1).

O Quadro 3 apresenta as descobertas da aplicação da ferramenta divididas em categorias indutivas da própria análise:

Quadro 3 Resultados da técnica Diagrama de afinidade aplicada para o presente estudo.

\begin{tabular}{|c|c|c|c|}
\hline & Área de busca de filtros & Filtros do feed & Biblioteca de filtros \\
\hline \multirow[t]{3}{*}{ Pontos Positivos } & $\begin{array}{l}\text { Fácil de utilizar para } \\
\text { buscas informais; }\end{array}$ & $\begin{array}{l}\text { Amigos são uma boa indicação } \\
\text { de filtros; }\end{array}$ & $\begin{array}{l}\text { É rápido transitar entre os } \\
\text { filtros disponíveis; }\end{array}$ \\
\hline & Prévia de filtros é útil; & \multirow{2}{*}{$\begin{array}{l}\text { É simples instalar filtros a partir } \\
\text { desta área. }\end{array}$} & \multirow{2}{*}{$\begin{array}{l}\text { Os ícones ajudam a identificar } \\
\text { como será o filtro, sem } \\
\text { necessidade de acessá-lo. }\end{array}$} \\
\hline & É fácil instalar filtros. & & \\
\hline \multirow[t]{6}{*}{ Pontos Negativos } & $\begin{array}{l}\text { Impossibilidade de busca } \\
\text { inserindo termos; }\end{array}$ & \multirow{3}{*}{$\begin{array}{l}\text { O tempo de um Stories é } \\
\text { insuficiente para toda a tarefa de } \\
\text { decidir por um filtro e instalá-lo. } \\
\text { É difícil recuperar a informação: } \\
\text { "Quem usou aquele filtro que } \\
\text { eu gostei?"; }\end{array}$} & \\
\hline & \multirow{2}{*}{$\begin{array}{l}\text { Falta de filtragens comuns a } \\
\text { áreas de busca: mais baixados, } \\
\text { mais novos, filtros semelhantes } \\
\text { e busca por usuários; }\end{array}$} & & \\
\hline & & & \\
\hline & $\begin{array}{l}\text { Impossibilidade do usuário inserir } \\
\text { suas próprias tags; }\end{array}$ & \multirow{3}{*}{$\begin{array}{l}\text { Faltam indicações de filtros } \\
\text { parecidos ao que está sendo } \\
\text { visualizado, outros filtros criados } \\
\text { pelo usuário etc. }\end{array}$} & \\
\hline & $\begin{array}{l}\text { Impossibilidade de visualizar } \\
\text { características do filtro, } \\
\text { principalmente quantidade } \\
\text { de memória que ocupará } \\
\text { quando instalado; }\end{array}$ & & \\
\hline & $\begin{array}{l}\text { Não há recomendações } \\
\text { personalizadas. }\end{array}$ & & \\
\hline
\end{tabular}




\subsection{Recomendações de melhorias}

Para Nielsen (2012), a usabilidade é crucial para o conteúdo da Internet e mesmo um aplicativo com mais de um bilhão de usuários ativos, como o Instagram (SHANE-SIMPSON, 2018), precisa considerar a qualidade da experiência em sua plataforma para continuar engajando tal audiência. Assim, é possível afirmar, baseado nas descobertas dos métodos de DCU aplicados, que tal a usabilidade e, de forma mais abrangente, a experiência de uso em tal plataforma pode ser melhorada com mudanças na forma de busca de sua área de filtros.

Sendo as interfaces estas camadas de comunicação entre usuários emitentes de comandos e artefatos que respondem (JETTER, 2013), fica evidente nas descobertas do DCU a necessidade dos usuários da plataforma em emitir comandos de busca que esta não permite.

Para alcançar o objetivo proposto, a aplicação das ferramentas de DCU necessitou abarçar os três pilares da Arquitetura da Informação (ROSENFELD; MORVILLE, 2006), trabalhando com usuários reais, em um contexto de uso que buscava um conteúdo específico.

Assim, baseados nas indicações dos usuários de problemas referentes à situação estudada, os pesquisadores voltaram-se a um exemplo de aplicação já estudada que possui características com potencial de ajudar resolver as dificuldades relatadas: o aplicativo móvel da plataforma de streaming de entretenimento Netflix (VENDRAMI JUNIOR; GONÇALVES, 2019).

Abaixo as recomendações deste estudo de melhorias para a área de busca de filtros de realidade aumentada do Instagram Stories:

- Dividir a área de busca em: busca por tags, palavras-chave e usuários;

- Dedicar uma aba para filtros mais utilizados pelos usuários da plataforma;

- Permitir que o resultado das buscas seja ordenado por: tamanho do filtro, quantidade de instalações, data de publicação e relevância em relação à palavra pesquisada;

- Indicar ao usuário filtros semelhantes ao selecionado;

- Permitir notificações quando da publicação de novos filtros por usuários selecionados;

- Permitir notificações quando da publicação de novos filtros associados a tags selecionadas;

- Criar seção com filtros utilizados por usuários seguidos pelo utilizador;

Na seção de criação do Stories:

- Possibilidade de agrupar filtros em pastas;

- Visualização de filtros estilo finder: miniaturas dos filtros, divididas em colunas, com possibilidade de, ao clicar em 
cada um, ver detalhes destes como tamanho, funcionalidade, desenvolvedor, desinstalação, filtros semelhantes a este e outros usuários que o utilizam;

- Possibilidade de reordenar e apagar filtros.

\section{Conclusões}

As formas de busca de filtros para Stories que o aplicativo do Instagram possui não são suficientes para atender as necessidades dos usuários, pois não foram atualizadas após a introdução dos filtros criados por usuários que, por sua quantidade, geraram uma nova dinâmica de utilização do sistema.

Assim, o objetivo desta pesquisa foi analisar, a partir do DCU, a interação e a resposta às tarefas realizadas pelos usuários nas áreas de busca de filtros no Instagram Stories e propor recomendações para sua melhorias ou redesenho.

Utilizando ferramentas de DCU Mapeamento de stakeholders, Grupo focal, Mapa da jornada do usuário, Diagrama de fluxo e Diagrama de afinidade, foi possível identificar os problemas que afetam a experiência dos usuários com as áreas citadas e recomendar melhorias.

O Mapeamento foi utilizado na identificação de usuários para aplicação das demais ferramentas e o Diagrama de fluxo foi utilizado como ferramenta acessória para planejar o Diagrama de afinidade.

O Mapa da jornada do usuário, além de revelar problemas enfrentados pelos usuários, permitindo entender o contexto de cada problema. Além disso, indicando porquê determinadas características eram problemáticas, permitiu inferir pistas de como alterá-las.

O Grupo focal e o Diagrama de afinidade identificaram o porquê, quando e como um problema ocorre. Vale ressaltar que o Diagrama de afinidade, com sua organização de temas e separação de problemas e qualidades foi a ferramenta que permitiu a maior clareza da situação de uso integral.

A fácil recuperação da informação por parte do usuário é crucial para uma boa experiência com aplicativos que disponibilizam grande quantidade de opções daquilo que exibem. Dessa forma, estudos para melhorar a qualidade da busca podem ser expandidos para outras situações, colaborando para melhorar a experiência dos usuários em muitas situações de uso e plataformas.

Como limitação e possibilidade de novos estudos, esta pesquisa foi desenvolvida com um grupo de usuários composto com base na percepção dos pesquisadores sobre o público de contas da plataforma a que possuíam acesso - dessa forma, uma ampliação do grupo estudado pode trazer novas descobertas.

A organização e busca de dados em aplicativos de celular com grande quantidade de informação é um desafio que não se esgota com o estudo de uma única situação. Assim, para futuros estudos recomendamos a análise baseada em ferramentas de DCU de 
mecanismos de pesquisa de outros aplicativos mobile com grande quantidade de conteúdo, como Airbnb, AppleTV+, Spotify etc.

\section{Referências}

ALVES, P. Instagram deixa usuários criarem filtros personalizados para Stories: qualquer pessoa pode criar seus próprios filtros 3D e disponibilizar na rede social. TechTudo. 2019. Disponível em: https://www.techtudo.com.br/ noticias/2019/o8/instagram-deixa-usuarios-criarem-filtros-personalizadospara-stories.ghtml. Acesso em: 5 dez. 2019.

CARDOSO, B. Instagram Stories faz 2 anos; veja a evolução da ferramenta: ferramenta de posts efêmeros do Instagram faz aniversário nesta quintafeira (2). TechTudo. 2018. Disponível em: https://www.techtudo.com. br/noticias/2018/o8/instagram-stories-faz-2-anos-veja-a-evolucao-daferramenta.ghtml. Acesso em: 5 dez. 2019.

COCKTON, G. Usability evaluation. In: SOEGAARD, M.; DAM, R. F. (orgs.). The encyclopedia of human-computer interaction. 2. ed. Aarhus: The Interaction Design Foundation. Disponível em: https://www.interactiondesign.org/ encyclope-dia/usability_evaluation.html. Acesso em: 17 dez. 2019.

GARRET, J. J. The elements of user experience: user-centered design for the web and beyound. 2. ed. Berkeley: New Riders, 2010.

FERreira, S. M. S. P. Novos paradigmas e novos usuários de informação. Ciência da Informação, Brasília, v. 25, n. 2, 1995. Disponível em: http://revista.ibict. br/ciinf/article/view/66o. Acesso em: 18 dez. 2019.

FROMMER, D. Here's how to use Instagram. Insider. 2010. Disponível em: https:// www.businessinsider.com/instagram-2010-11?op=1. Acesso em: 30 nov. 2019.

GEYSER, W. Instagram Stories AR filters: what are they and how are brands using them? Influencer Marketing Hub. 2019. Disponível em: https:// influencermarketinghub.com/instagram-stories-ar-filters/. Acesso em: 29 abr. 2019.

HANINGTON, B.; MARTIN, B. Universal methods of design. Beverly: Rockport Publishers, 2012.

JETTER, H. C. Blended interaction: envisioning future collaborative interactive spaces. In: ANNUAL CHI CONFERENCE ON HUMAN FACTORS IN COMPUTING systems, 31., 2013, Paris. Extended abstracts. New York: Association for Computing Machinery, 2013. p. 232-248.

LIMA-MARQUES, M.; MACEDO, F. L. O. Arquitetura da informação: base para a gestão do conhecimento. In: TARAPANOFF, K. O. (org.). Inteligência, informação e conhecimento. Brasília: IBICT, 2006. p. 241-255.

NIELSEN, J. Usability 101: introduction to usability. Nielsen Norman Group. 2012. Disponível em: https://www.nngroup.com/articles/usability-101introduction-to-usability/. Acesso em: 19 dez. 2019.

NORMAN, D.; NIELSEN, J. The definition of user experience (UX). Nielsen Norman Group. Disponível em: https://www.nngroup.com/articles/definition-userexperience/. Acesso em: 29 de abr. 2019. 
ROSENFELD, L.; MORVILLE, P. Information architecture for the world wide web. 3. ed. Sebastopol: O’Reilly Media Inc., 2006.

RUBIN, J. Handbook of usability testing: how to plan, design, and conduct effective tests. New York: John Wiley \& Sons, 1994.

SChmalstieg, D.; HOllerer, T. Augmented reality: principles and practice. Boston: Addison-Wesley Professional, 2016.

SHANE-Simpson, c. et al. Why do college students prefer Facebook, Twitter, or Instagram? Site affordances, tensions between privacy and self-expression, and implications for social capital. Computers in human behavior, [S.l.], v. 86, p. 276-288, 2018. DOI: 10.1016/j.chb.2018.04.041

VENDRAMI JUNIOR, D. G.; GONÇALVES, B. s. Interfaces de plataformas de streaming e mobilidade: avaliação de interfaces a partir de métodos de inspeção. In: CONGRESSO INTERNACIONAL DE DESIGN DA INFORMAÇÃO, 9., 2019, Belo Horizonte. Anais [...] São Paulo: Blucher, 2019, p. 1593-1603. DOI: 10.5151/9cidi-congic-4.0065.

WAKKA, W. Instagram bate marca de 1 bilhão de usuários ativos. Canaltech. 2018. Disponível em: https://canaltech.com.br/redes-sociais/instagram-batemarca-de-1-bilhao-de-usuarios-ativos-116344/. Acesso em: 4 dez. 2019. WURMAN, R. S. Information architects. 2. ed. Lakewood: Watson-Guptill, 1997.

\section{Sobre os autores}

\section{Dorival Germano Vendrami Junior}

jvendrami@me.com

Mestrando do Programa de Pós-Graduação em Design Universidade Federal de Santa Catarina

Florianópolis, sc

\section{Eugenio Andrés Díaz Merino}

eugenio.merino@ufsc.br

Professor do Programa de Pós-Graduação em Design

Universidade Federal de Santa Catarina

Florianópolis, sc

\section{Giselle Schmidt Alves Dias Merino}

gisellemerino@gmail.com

Professora do Programa de Pós-Graduação em Design

Universidade Federal de Santa Catarina

Florianópolis, SC

Artigo recebido em/Submission date: 20/7/2020

Artigo aprovado em/Approvement date: 8/2/2021 